\title{
DINÂMICA DA VIOLÊNCIA ENTRE CASAIS A PARTIR DA ÓTICA DA MULHER AGREDIDA NO BAIRRO TRINDADE, FLORIANÓPOLIS/SC
}

\author{
Carolina Carvalho ${ }^{1}$, Juliana Regina Destro ${ }^{1}$, Sabrina Blasius Faust ${ }^{1}$, Elza Berger Salema Coelho ${ }^{2}$, Antonio
} Fernando Boing ${ }^{3}$

\begin{abstract}
RESUMO: O presente artigo investiga os tipos de violência entre casais a partir da percepção das mulheres agredidas que frequentam o Centro de Saúde Trindade, em Florianópolis, Santa Catarina. Realizou-se uma pesquisa exploratória, descritiva, com 62 mulheres de idade entre 19 e 56 anos. As entrevistas foram realizadas durante as consultas de enfermagem. As prevalências de violência psicológica e violência física foram estimadas pelo questionário Conflict Tatics Sacles - Form R. Das 62 mulheres entrevistadas, 93,6\% sofreram violência; destas, 100\% afirmaram ter sofrido violência psicológica e 19\% violência física. O principal motivo para o início das agressões foi o ciúme que o parceiro demonstra pela mulher. A violência pode ser prevenida, para tanto é preciso que se implementem Políticas Públicas capazes de combater as suas causas, e que a sociedade e os serviços de saúde assumam também esta responsabilidade. PALAVRAS-CHAVE: Saúde pública; Violência doméstica; Saúde da mulher.
\end{abstract}

\section{VIOLENCE DYNAMICS AMONG COUPLES FROM THE PERSPECTIVE OF VIOLENTED WOMAN LIVING AT TRINDADE NEIGHBOURHOOD, FLORIANÓPOLIS/SC}

\begin{abstract}
This article investigates the types of violence among couples from the perspective of vioented women who attend Trindade Health Center in Florianópolis, Santa Catarina. We conducted an exploratory, descriptive research, with 62 women aged between 19 and 56 years. The interviews were conducted during visits by nurses. The prevalence of psychological and physical violence were estimated by the questionnaire Conflict Tatics Sacles - Form R. Of the 62 women surveyed $93.6 \%$ experienced violence, and $100 \%$ of these said they had suffered psychological violence and $19 \%$ physical violence. The main reason for starting the assault was jealousy demonstrated by the woman's partner. Violence can be prevented, to do so there's a need to implement public policies to combat it's causes, and that society and health services also assume this responsibility.
\end{abstract}

KEYWORDS: Public health; Domestic violence; Women's health.

\section{DINÁMICA DE LA VIOLENCIA ENTRE PAREJAS BAJO LA ÓPTICA DE LA MUJER AGREDIDA EN EL BARRIO TRINDADE, FLORIANÓPOLIS/SC}

RESUMEN: Este artículo investiga los tipos de violencia entre parejas bajo la percepción de mujeres agredidas que frecuentan el Centro de Salud Trindade, en Florianópolis, Santa Catarina. Se realizó una investigación exploratoria, descriptiva, con 62 mujeres de edad entre 19 y 56 años. Las entrevistas fueron realizadas durante las consultas de enfermería. Las prevalencias de violencia psicológica y violencia física fueron estimadas por el cuestionário Conflict Tatics Sacles - Form R. De las 62 mujeres entrevistadas, 93,6\% sufrieron violencia, y, de estas, 100\% afirmaron haber sufrido violencia psicológica y 19\%, violencia física. El principal motivo para las agresiones fueron celos que el compañero demuestra por la mujer. La violencia puede ser prevenida; para eso es necesario implementar Políticas Públicas capaces de combatir su causas, y que la sociedad y los servicios de salud asuman también esta responsabilidad.

PALABRAS CLAVE: Salud pública; Violencia doméstica; Salud de la mujer.

\footnotetext{
${ }^{1}$ Acadêmica do curso de Enfermagem da Universidade Federal de Santa Catarina-UFSC.

${ }^{2}$ Enfermeira. Doutor em Filosofia da Enfermagem. Professor Adjunto do Departamento de Saúde Pública da UFSC.

${ }^{3}$ Cirurgião Dentista. Doutor em Odontologia Social. Professor Adjunto do Departamento de Saúde Pública da UFSC.
}

Autor correspondente:

Elza Berger Salema Coelho

Universidade Federal de Santa Catarina

Campus Trindade - 88040-900 - Florianópolis-SC-Brasil

Recebido: 27/03/10

E-mail: elzacoelho@gmail.com

Aprovado: 10/05/10 


\section{INTRODUÇÃO}

Na década de 90, em âmbito mundial, oficialmente o setor saúde começou a assumir os acidentes e a violência não só como uma questão social, mas como de grande importância enquanto campo de pesquisa na área da saúde pública, não só pelo impacto que provocam na qualidade de vida; como lesões físicas, psíquicas e morais e exigências de atenção e cuidados dos serviços médico-hospitalares, mas também pela oportunidade de avançar numa concepção ampliada de saúde, onde a violência é objeto de intersetorialidade, na qual o campo médico-social se integra ${ }^{(1)}$.

Para a Organização Mundial da Saúde ${ }^{(2)}$ violência é o uso intencional da força física ou o poder, sob a forma de ameaça real, contra si mesmo, outra pessoa ou contra um grupo ou comunidade, que resulte ou tenha grande possibilidade de resultar em dano, morte, prejuízo psicológico, mau desenvolvimento ou privação.

A forma mais comum de violência contra a mulher é aquela cometida pelo parceiro íntimo, e que se refere a qualquer ato ou comportamento dentro de uma relação íntima que cause dano ${ }^{(3)}$.

No Brasil, um estudo de base populacional mediu a ocorrência de violência contra as mulheres, realizado com amostra de 2.502 mulheres de 15 anos ou mais; ele demonstrou que $43 \%$ das brasileiras declararam ter sofrido violência praticada por um homem; um terço admitiu ter sofrido alguma forma de violência física, $13 \%$ sexual e $27 \%$ psicológica. A expressão de violência por parceiro íntimo mais frequente é a da violência psicológica exclusiva, seguida pela forma física acompanhada da sexual, e pelas três formas juntas. A sobreposição destas diversas formas de violência corresponde a $20 \%$ dos casos e constituise situação extremamente grave $\mathrm{e}^{(4)}$.

A violência contra a mulher é um problema complexo, multifacetado, que destrói vidas e compromete o desenvolvimento pleno e integral de milhões de mulheres no Brasil e no mundo. No Brasil, 70\% dos crimes contra mulheres acontecem dentro de casa e o agressor é o marido ou o companheiro, e apenas 10 a $30 \%$ dos casos de violência contra a mulher são denunciados ${ }^{(5)}$.

Esses dados revelam o caráter privado deste tipo de violência e uma relativa tolerância social, que têm contribuído para inibir a visibilidade do problema em suas justas proporções ${ }^{(6)}$. As mulheres estão sujeitas à agressão principalmente por pessoas conhecidas, como familiares, maridos, companheiros ou ex-companheiros, fato que muitas vezes leva à violência repetitiva, que se torna crônica com o passar dos meses, anos ou até vidas inteiras.

As consequências da violência para a saúde da mulher são causadas por todos os tipos de violência, entretanto, as mulheres vítimas de violência física e sexual são as que mais utilizam os serviços de saúde ${ }^{(7)}$. Os serviços de saúde podem ter atuação significativa no sentido de reconhecer a importância, a magnitude e danos da violência para a saúde das mulheres e, para tanto, os profissionais de saúde necessitam ser capacitados para incluir a investigação sobre o tema no seu atendimento. Desta forma, poderão desenvolver um trabalho de conscientização nas comunidades, encorajando as vítimas a procurar serviços especializados e denunciar os agressores ${ }^{(8)}$.

Considerando que o registro e a falta de notificação da violência contra a mulher também é deficitário no contexto dos serviços de saúde, isso acarreta um entrave para a sua real visibilidade, para o seu dimensionamento epidemiológico e, consequentemente, para a criação de políticas públicas voltadas à sua prevenção( ${ }^{(9)}$. Neste contexto, o objetivo desta pesquisa foi identificar a dinâmica da violência entre casais a partir das mulheres que sofreram agressões

\section{METODOLOGIA}

Desenvolveu-se uma pesquisa exploratória, descritiva, no Centro de Saúde Trindade, em Florianópolis/SC; para tanto, foram entrevistadas 62 mulheres com idade entre 19 e 56 anos, com ou sem história anterior de violência. Aplicou-se o questionário Conflict Tactics Form $R$ (CTS-1), que foi adaptado de forma transcultural e validado para sua versão em português, utilizada para estimar a violência entre casais ${ }^{(10)}$. Foram elegíveis mulheres que tiveram qualquer tipo de relacionamento amoroso nos últimos 12 meses, com duração mínima de um mês.

As mulheres foram entrevistadas entre agosto e outubro de 2009 na Unidade Básica de Saúde da Trindade, durante as consultas de enfermagem, como em pré-natal, puericultura, puerpério e preventivo de câncer de colo uterino. As perguntas referentes à violência psicológica e verbal abordavam ocorrências como insultos, xingamentos, discussão, provocações e ameaças. As perguntas relacionadas à violência física abordavam empurrões, tapas, bofetadas, chutes, mordidas, sufocamento e uso de arma. 
O projeto foi submetido ao Comitê de Ética em Pesquisa da Universidade Federal de Santa Catarina e aprovado sob o número 184, e seguiu as recomendações da Resolução 196/1996 do Conselho Nacional de Saúde, que regulamenta investigações envolvendo seres humanos.

Os dados foram digitados em banco de dados construído no Programa EpiData 3.1. A consistência e análise dos dados foram realizadas no pacote estatístico Stata 9. Para analisar os tipos de agressão, dividiram-se as questões em duas categorias: violência psicológica e violência física.

\section{RESULTADOS E DISCUSSÕES}

A maioria das mulheres que fizeram parte do estudo, conforme a tabela $1,79 \%$ encontrava-se na faixa etária de 19 a 40 anos e $80,6 \%$ era casada. O tempo médio de união estável foi de 9,2 anos. A média do número de filhos era de 1,6 por mulher, e o sistema familiar era composto, em sua maioria (60\%), de 3 a 4 pessoa. A profissão predominante foi a de doméstica, somando $37,1 \%$. Encontramos 43,6\% das famílias em que tanto o homem quanto a mulher eram os responsáveis pelo sustento familiar, enquanto em $35,5 \%$ o homem foi único provedor e em $8,1 \%$ somente a mulher.

Tabela 1 - Descrição da amostra da pesquisa. Florianópolis, 2009

\begin{tabular}{lc}
\hline Variável & n (\%) \\
\hline Tempo de união & \\
Até 1 ano & $11(17,7)$ \\
De 2 a 5 anos & $19(30,7)$ \\
De 6 a 10 anos & $8(12,9)$ \\
De 11 a 15 anos & $12(19,3)$ \\
Acima de 15 anos & $12(19,3)$ \\
Ocupação da mulher & \\
Doméstica & $23(37,1)$ \\
Auxiliar de cozinha & $9(14,6)$ \\
Manicure & $4(6,4)$ \\
Do Lar & $4(6,4)$ \\
Outras & $15(24,2)$ \\
\hline
\end{tabular}

Os parceiros das mulheres pesquisadas tinham idade entre 19 a 40 anos, referentes a $75,8 \%$ da amostra. A profissão exercida foi diversificada, sendo, predominantemente, a de pedreiros, $\operatorname{com} 21 \%$, acompanhada de carpinteiro e pintor com 11,3\%.

Alguns autores ${ }^{(11)}$ colocam que as histórias de violência intrafamiliar evocam certo estereótipo como pobreza urbana, desemprego, embriaguez e homens brutais. No entanto ${ }^{(12)}$, o baixo nível socioeconômico não é, em suma, causa direta da violência conjugal, mas está associado a um estresse maior, causado por incertezas, condições econômicas precárias e promiscuidades, ou seja, frustração e estresse podem ser gatilhos situacionais para o desencadeamento de uma condição psicológica não compreendida e que desestabiliza o homem, levando-o à ação agressiva.

Evidenciamos que a prevalência das mulheres que sofreram algum tipo de violência foi de 93,6\%; destas, $100 \%$ afirmaram ter sofrido violência psicológica e $19 \%$ violência física. Cabe ressaltar que todas as mulheres que sofreram violência física sofreram também a psicológica. Das 62 mulheres entrevistas, apenas $6,4 \%$ não relatam nenhum tipo de violência entre os casais.

Chama a atenção, no presente estudo, a violência que as mulheres afirmaram cometer contra os parceiros, totalizando $93,6 \%$, sendo $100 \%$ caracterizadas como violência psicológica e $31 \%$ como violência física. A violência psicológica e física juntas representaram $31 \%$. Os dados demonstram que a violência entre os parceiros tem se mostrado de ambos os lados, situação esta que evidencia casais e/ou situações violentas.

A violência conjugal não necessariamente se mostra intensa ou permanente, mas como um estado da relação que pode oscilar. Segundo estudo ${ }^{(12)}$, a violência ocorre em ciclo, que expressa o modo de interação de diversos fatores num mesmo relacionamento de violência, por meio de fases que se sucedem, sendo que nem todos os momentos, necessariamente, são marcados pela agressão. $\mathrm{O}$ autor ainda esclarece que esse ciclo possui três fases distintas, que variam em relação à intensidade e ao tempo para um mesmo casal e entre casais diferentes, não aparecendo obrigatoriamente em todos os relacionamentos.

\section{Motivos das agressões entre casais}

O motivo para iniciar a agressão raramente é o comportamento da mulher, normalmente um acontecimento externo ou um estado interno do homem ${ }^{(12)}$. A seguir (Quadro 1) estão listadas as justificativas apresentadas pelas mulheres sobre os motivos das agressões.

De acordo com os resultados obtidos, foi 
possível constatar que $25,8 \%$ dos motivos para as agressões estavam relacionados ao ciúme que o parceiro demonstra pela mulher, e $16,1 \%$ não identificaram o motivo para o início da agressão. Segundo estudo $^{(13)}$, o ciúme remete claramente ao machismo, quando constitui um sentimento e uma prática de posse do homem sobre a mulher, o que vem marcado pelo desejo de mantê-la como propriedade exclusiva. Podemos associar a questão do ciúme, também, à percepção das mulheres de uma falsa valorização pelo homem.

Quadro 1 - Motivos para iniciarem as agressões, segundo justificativa das mulheres. Florianópolis, 2009

\begin{tabular}{|lcc|}
\hline Motivo da agressão & $\mathbf{n}$ & $\mathbf{\%}$ \\
Ciúme do parceiro & 16 & 25,8 \\
Sem motivo específico & 10 & 16,1 \\
Por ciúmes da parceira & 07 & 11,3 \\
Atividades sociais dele com os amigos & 07 & 11,3 \\
(futebol, bar) & & \\
Diferença de opiniões & 06 & 9,6 \\
Uso de álcool e drogas pelo parceiro & 04 & 6,5 \\
Estresse de ambos & 04 & 6,5 \\
Problemas com familiares do parceiro & 03 & 4,8 \\
Dificuldades financeiras & 03 & 4,8 \\
Por causa dos filhos & 02 & 3,2 \\
\hline
\end{tabular}

Os homens agressores podem ser enquadrados num perfil de consumo de álcool e drogas, ciúme patológico, transtornos de personalidade, falta de controle sobre a raiva, dificuldade de expressar sentimentos, distorções cognitivas sobre o papel da mulher e sobre o relacionamento, deficit de habilidades para comunicação e para resolução de problemas, além da baixa autoestima $^{(6)}$. Confirma os problemas relatados pelas mulheres pesquisadas sobre o início das discussões, registrando motivos como a falta de dinheiro, o estresse de ambos, uso de álcool e drogas pelo parceiro e a diferença de opiniões.

Apesar dos relatos de violência e agressões, quando questionadas sobre a nota que dariam para o seu relacionamento conjugal, $25,8 \%$ das mulheres deram nota igual ou inferior a sete e $74,2 \%$ deram nota igual ou superior a oito. Este fato pode se relacionar com a dependência psicológica e financeira que essas mulheres têm de seus parceiros, uma vez que se constatou que apenas $8,1 \%$ das mulheres dependem exclusivamente da renda do companheiro para seu sustento, enquanto $35,5 \%$ dependem do parceiro para sustentar a família e $43,6 \%$ dependem dele para complementar a renda familiar.

A forma mais comum de violência contra a mulher é aquela cometida pelo parceiro íntimo (namorado, companheiro, marido, ex-marido, ex-namorado). $\mathrm{O}$ fato de, em muitos casos, a mulher estar envolvida emocional e economicamente com o parceiro, implica na dinâmica da violência ${ }^{(3)}$.

\section{Tipos de Violência}

A violência pode ser psicológica ou física. As questões relacionadas a esses aspectos estão apresentadas na tabela 2 e discutidas a seguir.

Tabela 2 - Questões de violência do CTS-1. Florianópolis, 2009

\begin{tabular}{lcc}
\hline Questões de Violência & $\begin{array}{c}\text { Mulher } \\
\text { n (\%) }\end{array}$ & $\begin{array}{c}\text { Homem } \\
\text { n (\%) }\end{array}$ \\
\hline Violência Psicológica & & \\
Não discutiu calmamente o problema & $26(42)$ & $21(33,8)$ \\
Não conheceu o modo de pensar & $14(22,6)$ & $21(33,9)$ \\
Trouxe alguém para ajudar & $9(14,5)$ & $4(6,4)$ \\
Xingou ou insultou & $31(50)$ & $22(35,5)$ \\
Ficou emburrado, não falou mais & $47(75,8)$ & $39(62,9)$ \\
Retirou-se do local & $27(43,5)$ & $25(40,3)$ \\
Fez ou disse coisas para irritar & $24(38,7)$ & $29(46,8)$ \\
Ameaçou bater ou jogar coisas & $8(12,9)$ & $10(16,1)$ \\
Ameaçou com faca e arma & $2(3,2)$ & $2(3,2)$ \\
Violência Física & & \\
Jogou coisas & $7(11,3)$ & - \\
Empurrou ou agarrou & $12(19,4)$ & $8(12,9)$ \\
Deu tapa ou Bofetada & $2(3,2)$ & $6(9,7)$ \\
Chutou, mordeu, deu um murro & $6(9,7)$ & $2(3,2)$ \\
Bateu ou tentou bater com objetos & $3(4,9)$ & $1(1,6)$ \\
Espancou & - & $1(1,6)$ \\
Estrangulou ou sufocou & - & $2(3,2)$ \\
Usou faca ou arma & $1(1,6)$ & $1(1,6)$ \\
\hline & &
\end{tabular}

\section{Violência Psicológica}

Quanto às questões de violência psicológica apresentadas na tabela 2 , as prevalências foram idênticas quando comparadas entre mulheres e homens. Porém, quando analisada cada questão separadamente, esta prevalência foi maior nas mulheres, pois observamos que os homens discutem o problema mais calmamente e procuram conhecer melhor o modo da mulher pensar.

As mulheres xingam $15 \%$ mais que os homens durante as discussões; em contrapartida, quando houve 
discussão entre o casal, 14,5\% das mulheres tiveram a necessidade de trazer alguém para acalmar a situação, contra $6,4 \%$ dos homens. Podemos perceber neste estudo, referente à violência verbal, que diante de uma discussão as mulheres ficam mais "emburradas", não falam mais no assunto e retiram-se da discussão. Elas também fazem e dizem mais coisas para irritar os homens. Este fato pode ser explicado ao mostrar que em decorrência de sua menor força física e da expectativa da sociedade em relação à violência masculina, a mulher tende a especializar-se na violência verbal, mas que, sobremaneira, esse tipo de violência não é somente monopólio das mulheres ${ }^{(14)}$.

A violência psicológica, também conhecida por agressão emocional, às vezes tão ou mais prejudicial que a física, é vista pelo Ministério da Saúde, como toda ação ou omissão capaz de provocar ou objetivar causar dano à autoestima, à identidade ou ao desenvolvimento da pessoa, caracterizando-se como: insultos constantes; humilhação; desvalorização; chantagem; isolamento de amigos e familiares; ridicularização; rechaço; manipulação afetiva; exploração entre outras ${ }^{(15)}$.

As ameaças e o uso de objetos durante as discussões (quebrá-los, jogá-los) apresentam-se mais evidentes nas ações da mulher, sendo que neste tema (ameaça e uso de objetos), no geral, a mulher é mais agressiva que o homem. Podemos constatar que essa incidência de ameaças e uso de objetos ocorre após as agressões verbais.

Esses tipos de agressão causam geralmente menos danos físicos visíveis, e os materiais utilizados pela mulher para a agressão podem estar relacionados com sua menor força física. $O$ fato é que a mulher comete mais essa violência, joga objetos numa proporção de $11,3 \%$ para $0 \%$ dos homens, constituindo-se um mecanismo para revidar as agressões.

\section{Violência Física}

A dinâmica da violência de gênero deve ser entendida como uma relação de poder e dominação dos homens e de submissão das mulheres, que remete aos papéis impostos historicamente a ambos.

Conforme a tabela 2, o homem utiliza de sua maior força física para agredir a mulher, por meio de: espancamento e estrangulação e até a utilização de arma. Na agressão do tipo tapa ou bofetada, os homens praticam mais que as mulheres, numa proporção de $9,7 \%$ para $3,2 \%$. Os dados demonstram que $1,6 \%$ dos homens espancam as parceiras e 3,2\% as estrangulam e sufocam. Nestas situações, é comum trazer implícita a ideia de diferença social existente entre o homem e a mulher, que o coloca como detentor de maior liberdade e legitimidade para agredir e a ela como quem deve se submeter.

Foi evidenciado que os estudos de base populacional parecem detectar melhor os casos de violência moderada ${ }^{(16)}$, o que, erroneamente, poderia indicar maior violência perpetrada pela mulher em relação ao homem. Além disso, ressaltam-se as poucas indicações de que a mulher cometa agressões contra o parceiro na mesma intensidade e severidade de violência dirigida a ela pelo homem, conforme encontramos no presente estudo, em que as mulheres que empurraram, agarraram, morderam e bateram ou tentaram bater com objetos somaram $34 \%$, enquanto $17,7 \%$ dos homens apresentaram esta reação.

Ao analisar dados sobre violência entre parceiros íntimos na população de 18 a 28 anos nos Estados Unidos, pesquisadores ${ }^{(17)}$ descreveram que, em $24 \%$ dos relacionamentos, havia algum tipo de violência e que, em metade desses, os atos eram recíprocos entre homem e mulher. Nos casos de não reciprocidade, as mulheres foram as agressoras em cerca de $70 \%$ dos casos.

Nesse sentido, para o melhor entendimento dos atos de violência, é preciso considerar a dinâmica dessas relações e o contexto familiar que agem em conjunto com os demais fatores individuais e estruturais $^{(18)}$.

\section{CONSIDERAÇÕES FINAIS}

O estudo demonstrou o envolvimento dos parceiros em proporções semelhantes, chamando a atenção para um dado relevante, que foi a violência cometida pelas mulheres. É preciso que se implementem Políticas Públicas capazes de combater a violência e que a sociedade seja uma aliada na busca de estratégias para o enfrentamento da mesma.

Para tanto, também se faz necessário que as equipes de saúde estejam atentas e preparadas para atender esta demanda, considerando que a realidade da violência no cotidiano de homens e mulheres é fato evidente na literatura, porém, ainda assim, continua sendo invisível aos profissionais de saúde.

Consideramos que a violência psicológica é um dado importante para além da gravidade da violência entre os casais, e que as mulheres, seja por so- 
brecarga de funções ou necessidade de atenção, estão mais estressadas e intolerantes, acarretando um maior número de reclamações e insatisfações em relação ao parceiro. Outro dado relevante apresentado neste estudo foi que a violência física apareceu, na maioria dos casos, acompanhada da violência psicológica, e que os homens ainda cometem mais violência física do que as mulheres.

\section{REFERÊNCIAS}

1. Minayo MCS. A difícil e lenta entrada da violência na agenda do setor saúde. Cad Saúde Pública. 2004;20(3).646-7.

2. Organização Mundial da Saúde (OMS). Relatório mundial sobre violência e saúde. Brasília: OMS/Opas; 2002.

3. Krug EG, Dahlberg LL, Mercy JA, Zwi AB, Lozano $\mathrm{R}$. World report on violence and health. Geneve: World Health Organization; 2002.

4. Venturi G, Recamán M, Oliveira S, organizadores. A mulher brasileira nos espaços público e privado. São Paulo: Fundação Perseu Abramo; 2004.

5. Carreira D, Pandjiarjian V. Vem pra roda! Vem para rede! Guia de apoio à construção de redes de serviços para o enfrentamento da violência contra a mulher. São Paulo: Rede Mulher de Educação; 2003.

6. Sanmartín J. El labirinto de la violencia: causas, tipos y efectos. $2^{\mathrm{a}}$ ed. Barcelona: Ariel; 2004.

7. Venguer T, Fawcett G, Vernon R, Pick S. Violencia doméstica: un marco conceptual para la capacitación del personal de salud. INOPAL III Population Council; 1998.

8. Ferraz MIR, Labronici LM. Perfil da violência doméstica contra mulher em Guarapuava, Paraná. Cogitare Enferm. 2009;14(2):261-8.

9. Saliba O, Garbin CAS, Garbin AJI, Dossi AP. Responsabilidade do profissional de saúde sobre a notificação de casos de violência doméstica. Rev Saúde Pública. 2007;41(3):472-7.

10. Hasselmann MH, Reichenheim ME. Adaptação transcultural da versão em português da Conflict Tactics Scales Form R (CTS-1), usada para aferir violência no casal: equivalências semântica e de mensuração. Cad Saúde Pública. 2003;19(4):1083-93.
11. Minuchin S, Nichols MP. A cura da família. Porto Alegre: Artes Médicas; 1995.

12. Morrison AR, Biehl ML. A família ameaçada: violência doméstica nas Américas. Rio de Janeiro: FGV; 2000.

13. Lamoglia, CVA, Minayo MCS. Violência conjugal, um problema social e de saúde pública: estudo em uma delegacia no interior do Estado do Rio de Janeiro. Ciênc Saúde Colet. 2009; 14(2):595-604.

14. Ballone GJ, Ortolani IV. Violência doméstica. [Internet] 2003 [acesso em 5 maio 2009]. Disponível: http://tiny.cc/k7q83

15. Ministério da Saúde (BR). O Brasil no estudo multipaíses sobre saúde da mulher e violência doméstica e sexual contra a mulher: relatório preliminar. Brasília, DF: MS/Coord. Nac. de DST e AIDS/UNESCO; 2002

16. Johnson MP, Ferraro KJ. Research on domestic violence in the 1990s: making distinctions. J Marriage Fam. 2000;(62):948-63.

17. Whitaker DJ, Haileyesus T, Swahn M, Saltzman LS. Differences in frequency of violence and reported injury between relationships with reciprocal and nonreciprocal intimate partner violence. Am J Publ Health. 2007; 97:941-7.

18. Castro R, Riquer F. La investigación sobre violencia contra las mujeres en América Latina: entre el empirismo ciego y la teoría sin datos. Cad Saúde Pública. 2003; 19(1):135-46. 